\title{
Mecanismos de transmissão da política monetária e controle da inflação no Brasil
}

Marcos Wagner da Fonseca* José Luis Oreiro

O Banco Central do Brasil (BCB) vem realizando um controle rígido da inflação, obedecendo ao Regime de Metas de Inflação, adotado em 1999. Nos momentos em que a taxa de inflação esperada se descola do limite superior estabelecido pela meta, o BCB aumenta a taxa básica de juros da economia (SELIC).

Uma discussão realizada atualmente sobre esta sistemática de política monetária é sobre o grau e a intensidade da elevação da SELIC para contenção da aceleração inflacionária. Há setores, principalmente o industrial, que defendem que a política monetária estaria se adiantando demais aos movimentos da inflação e que a elevação da SELIC seria demasiada para os objetivos de manutenção da meta, caracterizando um overshooting desnecessário.

Tal como iremos argumentar a seguir, a análise da literatura teórica e empírica sobre os mecanismos da transmissão da política monetária nos permite concluir que a elasticidade juros da taxa de inflação no Brasil é baixa, sendo esta uma das razões pelas quais a taxa real de juros tem sido mantida em patamares elevadíssimos na economia brasileira. Para aumentar essa elasticidade é necessário que se adotem as seguintes políticas:

i) Desindexação da dívida mobiliária federal a taxa de juros básica da economia, de forma a reduzir ou eliminar o efeito renda resultante das elevações da SELIC.

ii) Implementação de controles a entrada de capitais estrangeiros no Brasil, com o objetivo de impedir ou reduzir a apreciação cambial resultante do aumento da taxa básica de juros; apreciação esta que estimula uma aceleração dos planos de investimento das firmas, contribuindo assim para a perpetuação das pressões de demanda agregada sobre a taxa de inflação.

iii) Adoção de uma política monetária menos restritiva de forma a permitir uma redução dos spreads bancários, aumentando assim a importância do canal do crédito na transmissão da política monetária.

\footnotetext{
* Professor da Universidade Estadual do Oeste do Paraná - UNIOESTE, Campus Cascavel e Doutorando em Desenvolvimento Econômico pela UFPR. E-mail: mwfonseca@bol.com.

** Doutor em Economia (IE/UFRJ), Professor do Departamento de Economia da UFPR e Pesquisador do CNPq. E-mail: joreiro@ufpr.br. Página pessoal: http://www.joseluisoreiro.ecn.br.
} 
Após estabilização dos preços e retomada do papel da política monetária, durante o Plano Real, estudos realizados tentam explicar o impacto que as alterações na SELIC podem provocar nas variáveis reais da economia e na taxa de inflação.

O BCB está inserido nestes estudos com a publicação dos textos para discussão (Working Papers Series) desde 2000. Obviamente, os textos para discussão refletem a opinião de seus autores e não do BCB. Contudo se a maior parte dos autores são membros do BCB e, especificamente, de seu Departamento de Pesquisa, conclui-se que o resultado de suas pesquisas seja para aplicação na operacionalidade da política monetária.

No primeiro texto para discussão ${ }^{14}$ da série é apresentado um conjunto de ferramentas que dão suporte ao processo de tomada de decisão em política monetária. Para construir este modelo macroeconômico estrutural se estudou e incorporou os vários canais de transmissão da política monetária, a saber: canal da taxa de juros, canal da taxa de câmbio, canal da demanda agregada, canal de preço de ativos, canal direto, canal de expectativas e canal do crédito. De acordo com as características macroeconômicas da economia brasileira, o estudo chegou as seguintes conclusões: (i) taxa de juros afeta o consumo de bens duráveis e de investimento num período entre 3 e 6 meses. A atuação sobre o gap do produto leva mais de 3 meses para atingir a inflação. Isto significa que, por meio do canal da demanda agregada, uma alteração na taxa de juros demora em torno de 9 meses para atingir a inflação; (ii) através do canal direto, percebe-se que modificações na taxa de juros nominal interferem na taxa de câmbio nominal e na inflação de maneira imediata. A chamada "inflação importada" seria a responsável por esta contemporaneidade; (iii) historicamente o Brasil apresentou um baixo nível de crédito como proporção do PIB e após o Plano Real isto ainda prevalece, indicando que o canal do crédito não tem operado de forma relevante na economia brasileira, assim não apresenta impacto significativo sobre a inflação.

Uma aplicação empírica do modelo levou aos seguintes resultados ${ }^{15}$ : o efeito da taxa de juros sobre a inflação é indireto e leva 2 trimestres para ocorrer. Um aumento de 1 ponto percentual na taxa de juros real poderá afetar negativamente o gap do produto em 0.39 pontos percentuais. Uma queda de 1 ponto percentual no gap do produto reduz a inflação em 0.31 pontos percentuais. Assim, o efeito final de um aumento de 1 ponto percentual na taxa de

\footnotetext{
${ }^{14}$ BOGDANSKI. J,; TOMBINI. A. A.; WERLANG. S. R. C. Implementing inflation targeting in Brazil. Working Paper Series n.1. Brasília: Banco Central do Brasil, julho, 2000.

15 Ver FREITAS, P. S. DE; MUINHOS, M. K. A simple model for inflation targeting in Brazil. Working Paper Series n. 18. Brasília: Banco Central do Brasil, abril, 2001.
} 
juros real terá uma redução de 0.12 pontos percentuais na inflação no curto prazo. No longo prazo, a tendência é que a redução da inflação seja maior, atingindo 0.6 ponto percentual.

Este modelo, apesar de ter sofrido atualização ao longo do tempo, é o responsável por fornecer subsídios a COPOM em sua tomada de decisão sobre o nível da SELIC que permitirá o cumprimento da meta. Avaliando os resultados acima, percebe-se que para diminuir a inflação é necessária uma elevação significativa da taxa de juros real. Estaria aqui a explicação para a condução da política monetária ainda na atualidade, realizada com overshooting e um lag de tempo significativamente antecipado.

Nesse contexto, o atual patamar da taxa real de juros no Brasil - em torno de $14 \%$ ao ano - pode ser explicado pela combinação da adoção de metas declinantes de inflação ${ }^{16}$ e baixa elasticidade juro da taxa de inflação. Com efeito, a inflação brasileira medida pelo IPCA foi de 7,6\% no ano de 2004. Para 2005, a meta de inflação é de 5,1\% de variação do IPCA com uma banda de variação de 2.5\% para cima ou para baixo. Se o Banco Central estivesse mirando o teto da meta (7.6\%), então não teria sido necessário o forte movimento de elevação da taxa de juros básica iniciado em setembro de 2004. Contudo, ao mirar o centro da meta de 2005, o Banco Central se comprometeu com a estratégia de reduzir a taxa de inflação em 2.5 pontos percentuais num curto período de tempo. Com base nos dados da elasticidade juro de longo-prazo da taxa de inflação apresentado anteriormente, uma redução de tal magnitude da taxa de inflação exigiria, por si só, um aumento de 4.16 pontos percentuais da taxa real de juros. Considerando que em setembro de 2004 a taxa real de juros brasileira estava em torno de 9.5 pontos percentuais, essa decisão do Banco Central implicava num aumento da taxa real de juros para, pelo menos, $13.66 \%$ ao ano em 2005.

Se uma das razões para o "problema dos juros" no Brasil é que a elasticidade-juros da inflação é baixa, mesmo para o longo-prazo, devemos nos indagar sobre as razões dessa baixa sensibilidade.

Certamente um dos fatores relevantes para explicar essa baixa sensibilidade é a indexação de boa parte dos títulos da dívida mobiliária federal a taxa de juros SELIC. Dessa forma, quando o Banco Central promove um aumento da taxa básica de juros - para fazer com que a taxa de inflação convirja para as metas inflacionárias - os possuidores de títulos do governo não sofrem nenhuma perda de capital, pois o pagamento de cupom é

\footnotetext{
${ }^{16}$ Sobre a relevância das metas declinantes de inflação para o "problema dos juros" no Brasil ver CURADO, M; OREIRO, J.L. (2005). "Metas de Inflação: uma avaliação do caso brasileiro". Indicadores Econômicos FEE, Vol. 33, N.2 pp. 127-146.
} 
automaticamente reajustado pelo novo valor da taxa de juros, impedindo assim que o preço dos títulos se reduza em função do aumento da taxa de desconto aplicada à série de pagamentos futuros.

Como não há perda de capital, o único efeito do aumento da taxa de juros para os possuidores de títulos do governo é aumentar o fluxo de renda na forma de recebimentos de juros sobre o estoque de títulos que os mesmos possuam. Em outras palavras, um aumento da taxa de juros pelo BCB tem um efeito renda positivo sobre os possuidores de títulos públicos, pelo menos, sobre aquela parcela dos títulos que está indexada pela SELIC. Esse efeito renda positivo atua em sentido oposto ao tradicional efeito substituição de elevações da taxa básica de juros, contribuindo - assim, para a manutenção das pressões de demanda agregada sobre a inflação.

Em outro texto para discussão ${ }^{17}$, a aplicação do modelo confirmou a relevância dos canais de transmissão da demanda agregada e taxa de câmbio. O resultado estimado, com dados trimestrais, mostrou que mudanças na SELIC demoram de 1 a 2 trimestres para atingir a demanda agregada. e, após modificar a demanda agregada, atinge a inflação após um trimestre.

Portanto, uma mudança na SELIC é transmitida para a inflação, por meio do canal da demanda agregada, em até três trimestres. A atuação do canal da taxa de câmbio ocorre num período muito curto, menor que um trimestre, com impacto reduzido em relação ao canal da demanda agregada.

Outros trabalhos foram elaborados recentemente, inclusive pelo $\mathrm{BCB}^{18}$, para tratar da atuação do canal do crédito na economia brasileira. Um relevante estudo sobre o tema vem do Departamento de Economia da Puc - Rio ${ }^{19}$, que estudou o canal do crédito como transmissor de choque de demanda, via balanços das empresas, atuando como um "multiplicador financeiro" desses choques e, ainda, apresentou evidência empírica da atuação deste "multiplicador financeiro" na economia brasileira por meio de movimentos da taxa de câmbio.

17 BOGDANSKI, J. ET ALL. Inflation targeting in Brazil: shocks, backward-looking prices and IMF conditionality. Working Paper Series n. 24. Brasília: Banco Central do Brasil, agosto, 2001.

18 Ver CHU, V. Y. T.; NAKANE, M. I. Credit channel without the LM curve. Working Paper Series n. 20. Brasília: Banco Central do Brasil, maio, 2001. Também CHU, V. Y. T. Credit channel with sovereign credit risk: an empirical test. Working Paper Series n. 51. Brasília: Banco Central do Brasil, setembro, 2002.

19 CARNEIRO, D. D.; SALLES, F. M.; WU, T. Juros, câmbio e as imperfeições do canal do crédito. Texto para Discussão n. 480. Rio de Janeiro: Departamento de Economia Puc - Rio, dezembro, 2003. 
Uma conclusão do estudo é que um aumento na taxa de juros reduz a capacidade das firmas de se endividarem, diminuindo o número de projetos de investimentos que são efetivamente financiados e realizados. Os resultados sugerem que a elevação de juros é eficaz para provocar uma queda no nível de atividade, por meio de uma redução no nível de investimento. Estimou-se que, para cada 1\% de aumento na taxa de juros real, o total de crédito demandado cai em, aproximadamente, $2 \%$.

Outra conclusão é sobre as imperfeições típicas do mercado de crédito que ajudam a propagar e amplificar certos choques temporários. Verificou-se que a exigência de garantias, ou colateral, resulta numa imperfeição e que, ao exigir uma proporção do crédito como garantia, o nível de investimento total passe a ser um múltiplo do que as firmas podem oferecer como colateral. Assim, as mesmas podem oferecer, no máximo, todo o valor líquido dado pelo seu balanço patrimonial. Portanto, choques que afetem de maneira negativa o balanço das empresas, podem fazer com que as firmas percam acesso a fundos necessários à realização do investimento. Ou seja, essa imperfeição no mercado de crédito funciona como um "multiplicador financeiro" de choques sobre a demanda agregada.

De acordo com estimativas empíricas realizadas nesse estudo, um aumento de 1 ponto percentual na taxa de juros real anualizada reduz em 0.44 pontos percentuais a taxa de crescimento do investimento. Um dado importante do estudo diz respeito à relação obtida entre a taxa de câmbio e o nível de investimento. Para cada 1 ponto percentual de desvalorização cambial real, a taxa de crescimento do investimento foi reduzida em 0.35 pontos percentuais. Deveria se esperar uma relação positiva, mas ao re-estimar a equação de demanda por crédito, incluindo a desvalorização cambial como variável explicativa, obteve-se um coeficiente negativo e significativo. Assim, uma desvalorização de 1\% reduz a capacidade da firma se endividar em $0,35 \%$. Este efeito é superior ao efeito da taxa de juros real.

Esses resultados empíricos abrem espaço para a contestação da forma de condução da política monetária no Brasil. Com efeito, durante 2005, ocorreu uma valorização significativa do Real. Com base nas estimativas de Carneiro el alli (2003), essa valorização do câmbio real tende a produzir uma aceleração do investimento devido ao efeito da apreciação cambial sobre o balanço patrimonial das empresas, contribuindo, assim, para uma expansão da demanda agregada. Essa expansão da demanda agregada contribui para aumentar o gap do produto, tornando difícil ou até mesmo impedindo a queda da taxa de inflação. Como corolário dessas conclusões, segue-se que o BCB poderia aumentar a eficácia dos juros no combate a inflação (ou seja, a elasticidade juros da taxa de inflação) por intermédio de 
políticas que impedissem ou reduzissem a apreciação cambial como resultado da elevação da taxa de juros. Claramente tais políticas envolvem a adoção de controles a entrada de capitais como os adotados pelo Chile na década de $1990^{20}$.

No trabalho de Souza Sobrinho ${ }^{21}$ o objetivo é encontrar evidências empíricas para o canal do crédito via canal de empréstimos bancários (banking lending channel), a partir da análise de dados agregados do mercado de crédito, para o período Pós-Plano Real. Ao apresentar a evidência empírica, o autor defende que a autoridade monetária deveria realizar melhor uso dos indicadores de crédito nas decisões de política (questão de eficácia) e, ainda, deveria realizar uma avaliação criteriosa dos efeitos assimétricos da política sobre a economia real (questão de eficiência).

As evidências empíricas realizadas para o Brasil podem ser assim resumidas. A queda do produto real provocada pela contração monetária é ineficiente, pois a maior parte do custo é suportada pelas firmas que supostamente possuem as oportunidades de investimentos mais lucrativas (firmas pequenas, jovens e com alta taxa de crescimento). $\mathrm{Na}$ análise descritiva $\mathrm{O}$ autor avaliou cinco fatos estilizados, verificando se as informações corroboram ou não a intensidade de ocorrência dos mesmos.

O primeiro é quanto à razão crédito/PIB ser baixa, se comparada a outras economias. Souza Sobrinho afirma que as empresas brasileiras são pouco alavancadas em relação ao capital total, mas que, ao analisar a estrutura de dívida das empresas, percebeu-se que $45 \%$ do endividamento total é constituído de dívida bancária, percentual este bastante superior aos demais países. Desta forma, apesar da baixa relação crédito/PIB, as empresas são dependentes dos bancos no Brasil, sendo esta uma das condições necessárias para a operação do canal do crédito.

O segundo fato estilizado é quanto à proporção crédito/PIB ter sido declinante nos últimos anos. De 35\% do PIB, em 1995, passou para 27\%, no final de 2001. O aumento da dívida pública por emissão de títulos e as regras mais rígidas adotadas, com base no acordo da Basiléia, podem ter criado esta queda na relação crédito/PIB. Isto reduziria a importância do

\footnotetext{
${ }^{20}$ Uma proposta de adoção de controles de capitais na economia brasileira foi formulada por Oreiro, J.L; Paula, L.F. (2005). Strategy for Economic Growth in Brazil: a Post Keynesian approach. Texto para Discussão 23/2005. Curitiba: Departamento de Economia da UFPR. Disponível em www.economia.ufpr.br/publica/textos/textos.htm. ${ }^{21}$ Souza Sobrinho, N. F. Avaliação do Canal de Crédito no Brasil. Dissertação de Mestrado. IPE - USP. 2002.
} 
canal do crédito, porém, os testes econométricos indicam que mesmo neste ambiente o crédito desempenha um papel importante na transmissão da política monetária.

O terceiro fato estilizado é sobre o spread bancário ser excessivamente elevado no Brasil, mesmo levando em conta a tendência de queda que se tem observado. No mês de pico, durante o período de análise, os indivíduos chegaram a pagar 5,2\% a.m., ou 84\% a.a., em termos reais. $\mathrm{O}$ autor coloca que um spread estruturalmente elevado tem implicações importantes para o mecanismo de transmissão monetária. De fato, um spread elevado resulta numa baixa concessão de crédito por parte dos bancos comerciais e, dessa forma, numa baixa relação crédito/PIB. Isso reduz a importância do canal do crédito na transmissão dos efeitos da política monetária sobre o nível de atividade econômica e, conseqüentemente, sobre a taxa de inflação.

O quarto fato estilizado é sobre a maturidade das operações de crédito ser curta. Souza Sobrinho expõe que $80 \%$ do volume de crédito-pré possuem prazo médio inferior a um ano, tendo média ponderada de 7,2 meses. Isto torna a reação do mercado de crédito e da economia real mais rápida à ocorrência de choques monetários.

O quinto fato estilizado é que a relação entre política monetária, mercado de crédito e produto real parece se comportar no Brasil, de acordo com o previsto pela visão do crédito. Há uma relação inversa entre spread bancário médio e o crédito-pré e, ainda, uma relação positiva entre a SELIC e taxa média sobre empréstimos. O spread bancário demonstra uma relação negativa com o produto e positiva com o crédito.

Através do modelo VAR, Souza Sobrinho estimou as funções de resposta a impulso (FRIs) das variáveis de interesse. As conclusões que podem ser tiradas das FRIs são: (i) o produto real e o mercado de crédito reagem muito rapidamente aos choques monetários. A velocidade de reação está associada a uma importante característica do sistema bancário brasileiro, que é a curta maturidade dos contratos de empréstimos; (ii) o comportamento dos títulos e dos indicadores de crédito mostra que os bancos brasileiros respondem às incertezas em suas fontes de recursos, adotando uma estratégia de alocação de portfolio mais conservadora, eles aumentam sua carteira de ativos líquidos (títulos) e reduzem sua exposição a ativos ilíquidos (crédito). Tal comportamento sugere que a contração monetária induz a realocação do porffolio dos bancos em favor de títulos públicos, com conseqüente queda da oferta de crédito, elevação do spread bancário e contração do produto real; (iii) o impacto da contração monetária sobre a economia real, por via do canal do crédito, é assimétrico, pois 
afeta com maior intensidade os setores intensivos em capital de giro, cuja dependência dos empréstimos bancários de curto prazo é relativamente maior.

Para concluir, Souza Sobrinho sugeriu algumas implicações de política monetária que decorrem dos resultados apresentados no trabalho. O primeiro é sobre a eficácia de políticas monetárias excessivamente contracionistas. Sendo verdade que o spread responde às mudanças na SELIC, uma política monetária menos severa teria um impacto menor sobre o spread, podendo até mesmo reduzi-lo, contribuindo, dessa forma, para ampliar o canal do crédito e, portanto, garantindo uma maior eficácia da política monetária, ou seja, uma redução mais forte da inflação por intermédio de uma elevação menor da taxa real de juros. 